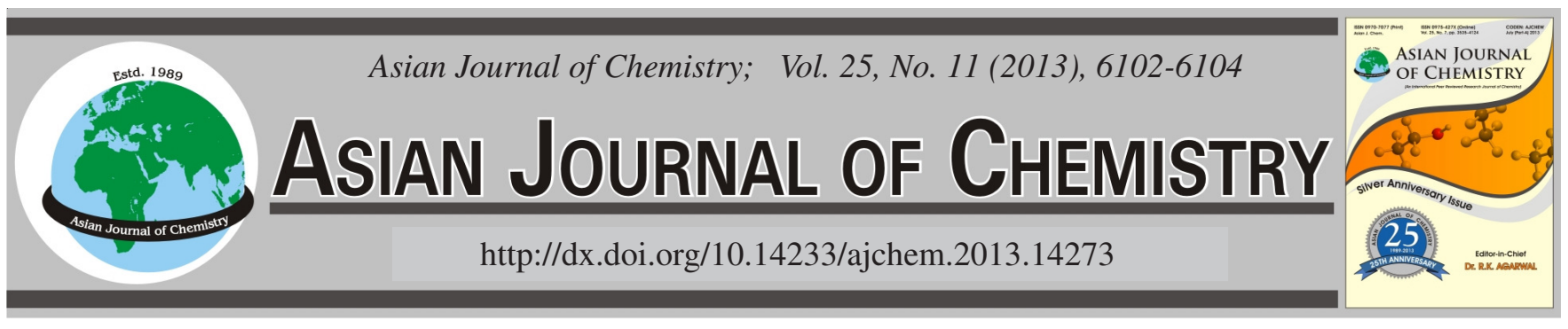

\title{
Microwave Assisted Synthesis of meso-Tetraphenylporphyrin and Its Application for Trace Metal Spectrophotometric Determination
}

\author{
M.H. GiviAnRAD ${ }^{*}$ and A. BAHRAMI
}

Department of Chemistry, Science and Research Branch, Islamic Azad University, Tehran, Iran

*Corresponding author: Fax: +98 21 44868445; Tel: +98 21 44868449; E-mail: givianradh@yahoo.com

The synthesis of meso-tetraphenylporphyrin with quantitative yield in presence of $p$-toluene sulfonic acid as new catalyst under microwave irradiation was accomplished. The meso-tetraphenylporphyrin was characterized by means of elemental analysis, UV-visible spectra, ${ }^{1} \mathrm{H}$ NMR spectra, infrared spectra and was used as chelating agent for direct determination of zinc ions by UV-visible spectroscopy.

Key Words: Microwave, Meso-tetraphenylporphyrin, Zinc, UV-visible spectroscopy.

\section{INTRODUCTION}

The porphyrins comprise an important class of macrocyclic compounds that serve nature in a variety of ways. The metalloporphyrin rings play an important role in important biological systems. They have also been verified as efficient sentitizers and catalyst in a number of chemical processes ${ }^{1,2}$.

Traditionally, porphyrins and metalloporphyrins syntheses have been carried out in acidic conditions such as propanoic acid or in a halogenated solvent ${ }^{3-5}$. In most cases, toxic oxidizing reagents are used to convert the initial porphyrinogen product to porphyrin. The porphyrin nucleus is a tetradentate ligand in with the space available for a coordinated metal has maximum diameter of approximately $3.7 \AA$. The porphyrin ring system and the porphyrin complexes with transition metal ions are very stable ${ }^{6}$.

The application and importance of porphyrins and metalloporphyrins have gained increasing interest in last decades in analytical chemistry, significantly. The porphyrins are one class of superior colourimetric compounds that became useful as the reagents in spectrophotometric methods for the determination of metal ions. Application of porphyrins as spectrophotometric reagents have two problems, the first one is that the absorption spectra of the reagent often overlaps with metal chelates and the second one is that the rate of reaction is lower than with the common reagent?

In this paper meso-tetraphenylporphyrin has been synthesized promptly, by combination of pyrrole and benzaldehyde under microwave irradiation ${ }^{8}$. Moreover, it has been characterized with UV-visible spectra, H NMR spectra, infrared spectra. The complex of zinc meso-tetraphenylporphyrin was formed in room temperature and was used for direct determination of zinc ions.

EXPERIMENTAL

All of materials were prepared in the quartz vessel. The microwave oven used for synthesis of tetraphenylporphyrin was LG, intellowave, $1000 \mathrm{~W}$. UV-VIS spectra were measured by Cary 100 Cone UV-VIS system. H NMR Spectra and FT-IR spectra were recorded by Bruker, $300 \mathrm{MHz}, 7 \mathrm{~T}$, FT-H NMR system and thermo Nicolet FT-IR system, respectively. All experimental procedures were performed at room temperature.

All the reagents were used without more purification and were of analytical grade. Glacial acetic acid was prepared by adding $20 \mathrm{~mL}$ acetic anhydride to 1 liter glacial acetic acid.

Synthesis of meso-tetraphenylporphyrin: The mesotetraphenylporphyrin was synthesized by reaction of pyrrole $(0.4 \mathrm{~mL})$ with benzaldehyde $(0.53 \mathrm{~mL})$ and $0.05 \mathrm{~g}$ of $p$-toluene sulfonic acid in a Pyrex bottle under microwave irradiation at 2 min intervals for $10 \mathrm{~min}$. Catalyst was removed by filtration and washed thoroughly with ultrapure water. A chromatographic column for separation of product mixture was prepared by applying the silica gel (100-200 mesh size) and hexane eluting with 7:1 (v/v) hexane-ethyl acetate solution.

Accordingly, the meso-tetraphenylporphyrin was prepared and characterized by UV-visible, H NMR and FT-IR spectrometry. UV-VIS spectroscopy showed the characteristic soret band at $418 \mathrm{~nm}$ and Q band at 511, 544, 594 and $653 \mathrm{~nm}$ in toluene. The IR spectrum of $\mathrm{H}_{2}$ TPP in $\mathrm{KBr}$ exhibited at 3430 , 3314, 3140, 3054, 3021, 2920, 2856, 2603, 2529, 2352, 2257 , $1886,1469,1399,990,962,955,798,646$ and $556 \mathrm{~cm}^{-1}$. Furthermore, H NMR spectrum and chemical shifts as shown in Table1 indicates the meso-substituted porphyrin structure. 


\begin{tabular}{cccccc}
\hline \multicolumn{5}{c}{ TABLE-1 } \\
\multicolumn{5}{c}{ HNMR CHEMICAL SHIFTS ( $\Delta$ [P.P.M.] FROM TMS) OF } \\
meso-TETRAPHENYLPORPHYRIN \\
\hline $\begin{array}{c}\text { Parent } \\
\text { compound }\end{array}$ & $\begin{array}{c}\text { meso Subst- } \\
\text { ituent (Position) }\end{array}$ & NH & Substituent- & Pyrrole & Solvent \\
& & & $\mathrm{H}$ & $-\mathrm{H}$ & \\
Porphyrin & $\left(\mathrm{C}_{6} \mathrm{H}_{5}\right)_{4}$ & 3.6 & 8.08 & 7.27 & \\
& & 0 & 8.59 & 7.76 & $\mathrm{CDCl}_{3}$ \\
& & & 8.86 & 7.97 & \\
\hline
\end{tabular}

Preparation of solution: Glacial acetic acid was prepared by adding $20 \mathrm{~mL}$ of acetic anhydride to $1 \mathrm{~L}$ glacial acetic acid. At least $12 \mathrm{~h}$ before used the meso-tetraphenylporphyrin solution was prepared by refluxing $0.269 \mathrm{~g}$ of meso-tetraphenylporphyrin in $250 \mathrm{~mL}$ glacial acetic acid for $7 \mathrm{~h}$. Zinc acetate solution was prepared by dissolving reagent grade metal acetates in glacial acetic acid. The acid was kept hot and water added slowly in $0.5 \mathrm{~mL}$.

\section{RESULTS AND DISCUSSION}

Microwave assisted procedure: Microwave irradiation has recently been a fast procedure for chemical synthesis ${ }^{9-12}$. In this paper, the procedure for preparation of mesotetraphenylporphyrin, take only $10 \mathrm{~min}$. However, the classical methods present some experimental limitations likes, long reaction times and sometimes low yields. These limitations are not associated with microwave irradiation ${ }^{13,14}$. No solvent is necessary in the reactions described in this study and the reaction condition is moderate. The synthesis reactions have been successfully repeated several times with identical results.

Determination of zinc: The zinc meso-tetraphenylporphyrin complex was established, as soon as zinc acetate was added to a solution of meso-tetraphenylporphyrin in glacial acetic acid after 50-60 min at room temperature. The absorption band of the complex was diminished at $551 \mathrm{~nm}$ (Fig. 1).

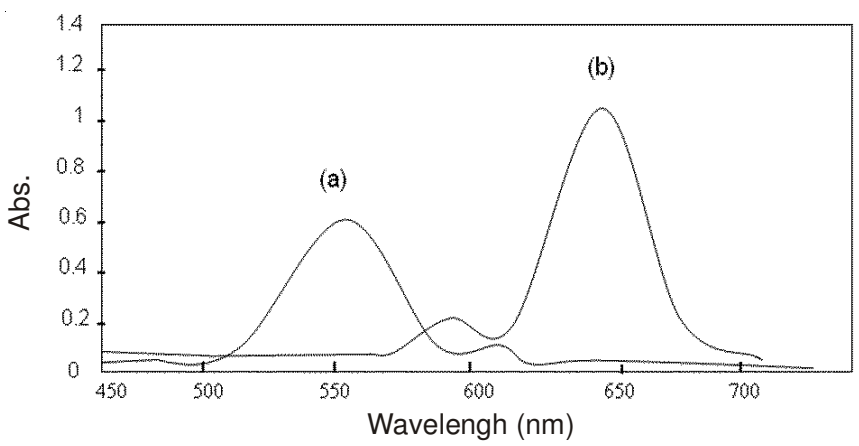

Fig. 1. (a) Absorption spectra of zinc tetraphenylporphyrin complex in glacial acetic acid; (b) Absorption spectra of meso-tetraphenylporphyrin complex in glacial acetic acid

The calibration curve was organized by transferring zinc acetate solution into series of $25 \mathrm{~mL}$ volumetric flasks and adding appropriate aliquots of the meso-tetraphenylporphyrin solution to each of them. Following 50 min the absorbance at $551 \mathrm{~nm}$ was read against a reference solution. The calibration curve parameters are given in Table-2.

Sample was dissolved and prepared to yield the same concentration, as was used in the calibration curve. The same amount of meso-tetraphenylporphyrin was added and after $1 \mathrm{~h}$ the absorbance was read. Calibration curve was applied for determination of the zinc ion of the samples (Table-3).

TABLE-2

PARAMETERS FOR CALIBRATION CURVE

\begin{tabular}{lcccc}
\hline Samples & $\begin{array}{c}\text { Wavelength } \\
(\mathrm{nm})\end{array}$ & $\begin{array}{c}\text { Quantitative } \\
\text { range }\left(\mathrm{mg} \mathrm{L}^{-1}\right)\end{array}$ & $\mathrm{R}^{\mathrm{a}}$ & $\begin{array}{c}\mathrm{RSD}^{\mathrm{b}} \\
(\%)\end{array}$ \\
\hline Zinc acetate & 551 & $0.8-8.0$ & 0.991 & 3.1 \\
Zinc perchlorate & 551 & $0.8-8.0$ & 0.986 & 5.9 \\
\hline
\end{tabular}

${ }^{\mathrm{a}}$ Correlation coefficient; ${ }^{\mathrm{b}}$ Relative Standard Deviation

TABLE-3

CONCENTRATIONS OF THE ZINC METAL IONS IN SAMPLES

\begin{tabular}{lcc}
\hline \multirow{2}{*}{ Sample } & \multicolumn{2}{c}{ Metal $\mathrm{Zn}^{2+}\left(\mathrm{mg} \mathrm{L}^{-1}\right)$} \\
\cline { 2 - 3 } & Added & Founded \\
\hline Sample a & 2.00 & 2.50 \\
Sample b & 5.00 & 5.12 \\
Sample c & 7.00 & 6.93 \\
\hline
\end{tabular}

Interferences: In this study interference of $\mathrm{Mg}(\mathrm{II}), \mathrm{Co}(\mathrm{II})$, $\mathrm{Fe}(\mathrm{II})$ and $\mathrm{Cu}$ (II) ions, which are likely to form complexes with meso-tetraphenylporphyrin in acetic acid was investigated (Table-4). In quantitative determination of zinc with complex formation, the most interaction was absorbed in presence of copper ions, Due to the similarity of the absorption spectra and also molar absorptivities of two metal complexes.

\begin{tabular}{|c|c|c|c|c|c|c|}
\hline \multicolumn{7}{|c|}{$\begin{array}{c}\text { TABLE-4 } \\
\text { THE INTERFERENCE OF THE METAL }\end{array}$} \\
\hline \multirow[t]{2}{*}{ Salt } & \multirow[t]{2}{*}{ Reagent } & \multirow[t]{2}{*}{$\begin{array}{l}\text { Wavelength } \\
\quad(\mathrm{nm})\end{array}$} & \multicolumn{4}{|c|}{$\begin{array}{l}\text { Tolerable level of interference } \\
\text { concentration }\left(\mathrm{mg} \mathrm{L}^{-1}\right)\end{array}$} \\
\hline & & & $\mathrm{Cu}(\mathrm{II})$ & $\mathrm{Fe}(\mathrm{II})$ & $\mathrm{Co}$ (II) & $\mathrm{Mg}(\mathrm{II})$ \\
\hline $\begin{array}{l}\text { Zinc } \\
\text { acetate }\end{array}$ & TPP & 551 & N. $D^{a}$ & 223 & 235 & 4.8 \\
\hline
\end{tabular}

Effect of metal salt: The absorbance of two identical solutions of meso- tetraphenylporphyrin with zinc acetate and meso-tetraphenylporphyrin with zinc perchlorate at $551 \mathrm{~nm}$ was compared. Consequently, as shown in Table-2, the absorbance was increased when zinc was added as zinc acetate. Moreover, according to the theory of solvent systems acetate salt functions as base and increases the concentration of the solvent anion ${ }^{15}$.

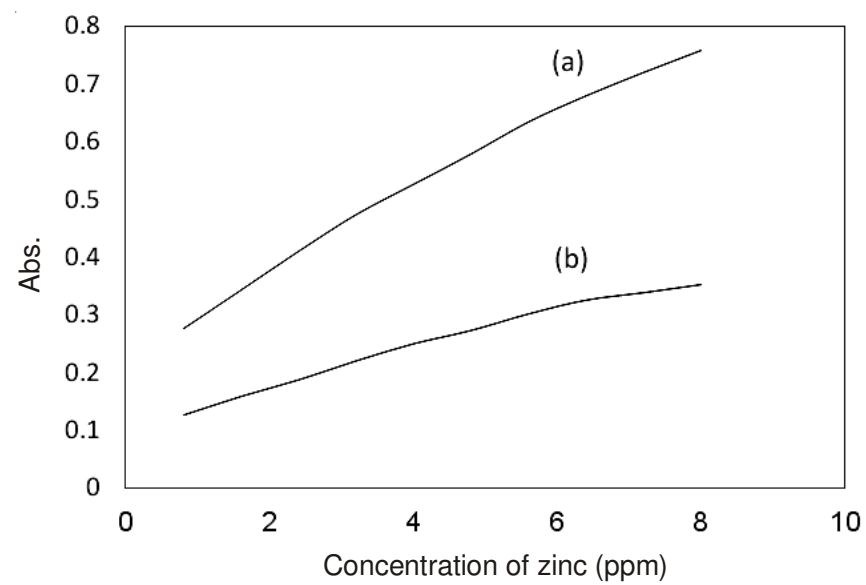

Fig. 2. (a) ZnTPP calibration curve with zinc acetate (b) ZnTPP calibration curve with zinc perchlorate 


\section{Conclusion}

meso-Tetraphenylporphyrin was synthesized by microwave irradiation with innovative, effective and available catalyst in $10 \mathrm{~min}$ with enhanced yield. Spectrophotometry property of the porphyrin was applied to obtain the concentration of zinc ions in the samples. Consequently, this study offers a simple and appropriate method for indirect spectrophotometric determination of metal ions, chelates, porphyrins and metalloporphyrins, which could be dissociated in acetic acid by effect on the complex formation equilibrium and changes in the absorbance at $551 \mathrm{~nm}$.

\section{ACKNOWLEDGEMENTS}

The authors are grateful to the Laboratory Complex of Islamic Azad University for valuable technical assistance.

\section{REFERENCES}

1. K.M. Smith, Porphyrins and Metalloporphyrins, Ed. Elsevier, Amsterdam (1975).

2. L.R. Milgrom, The Colours of Life, Oxford Press, New York (1997)
3. H. Fischer and A. Stern, Die Chemie Des Pyrroles, 2, 48 (1940).

4. D.F. Marsh and L.M. Mink, J. Chem. Ed., 73, 1181 (1996).

5. R. Lemberg and J.W. Legge, Haematin Compoundsand Bile Pigments, Interscience, New York (1949).

6. J.E. Falk, Porphyrins and Metalloporphyrins, Elsevier, New York (1975).

7. M. Biesaga, K. Pyrzynska and M. Trojanowicz, Talanta, 51, 209 (2000).

8. R.F. Beeston, S.E. Stitzel and M.A. Rhea, J. Chem. Educ., 74, 1468 (1997).

9. A. Loupy, A. Petit, J. Hamelin, F. Texier-Boullet, P. Jacquault and P. Mathe, Synthesis, 1213 (1998)

10. I. Elghamry and L.F. Tietze, Tetrahedron Lett., 49, 3972 (2008).

11. M.O. Liu, Ch.H. Tai, W.Y. Wang, J.R. Chen, A.T. Hu and T.H. Wei, J. Organomet. Chem., 689, 1078 (2004).

12. M. Chandrasekharam, Ch.S. Rao, S.P. Singh, M.L. Kantam, M.R. Reddy, P.Y. Reddy and T. Toru, Tetrahedron Lett., 48, 2627 (2007).

13. Y. Nagao, T. Naito, Y. Abe and T. Misono, Dyes Pigments, 32, 71 (1996).

14. R. Bonnett, S. Loannou, A.G. James, C.W. Pitt and M.M. Soe, J. Mater. Chem., 3, 793 (1993).

15. E.C. Franklin, J. Am. Chem. Soc., 46, 2137 (1924). 